\title{
La diplomacia española en la cuenca del Caribe durante la última crisis cubana (1895-1898)
}

\author{
Agustín Sánchez Andrés \\ CONSEJO SUPERIOR DE INVESTIGACIONES CIENTÍFICAS
}

MADRID

El desarrollo de la crisis cubana condicionó la política española hacia la cuenca del Caribe y convirtió a esta zona en un área prioritaria para la diplomacia española. En este marco, España estableció una política común hacia el conjunto de la región que, no obstante, se tradujo en la adopción de distintas estrategias hacia cada uno de los estados de la misma.

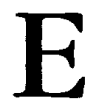

l estallido de una nueva crisis colonial en Cuba, en febrero de 1895, convirtió a la cuenca del Caribe en una zona de vital interés para la diplomacia española y condujo al gobierno español a adoptar una doble estrategia hacia el conjunto de esta región. ${ }^{1}$ Fue así que los representantes españoles en el área intentaron, por una parte, establecer un siste-

${ }^{1}$ La región conceptuada en este artículo en un sentido amplio como cuenca del Caribe, comprende tanto las Antillas -el denominado Caribe Insular- como aquellos estados del continente ribereños al mar Caribe. ma de inteligencia que permitiera desarticular las redes de apoyo organizadas por los revolucionarios cubanos en la cuenca del Caribe. ${ }^{2}$ Por otra parte, la diplomacia ibera presionó a los distintos gobiernos de la región para así restringir las actividades de los independentistas cubanos en sus respectivos territorios y utilizaran su influencia para contrarrestar la simpatía que la causa cubana despertaba entre la

${ }^{2}$ Instrucciones del Ministerio de Estado a las legaciones en Hispanoamérica, $7 \mathrm{dc}$ dic. de 1895, Archivo del Ministerio de Asuntos Exteriores (en adelante AMAE), leg. H-2896. 


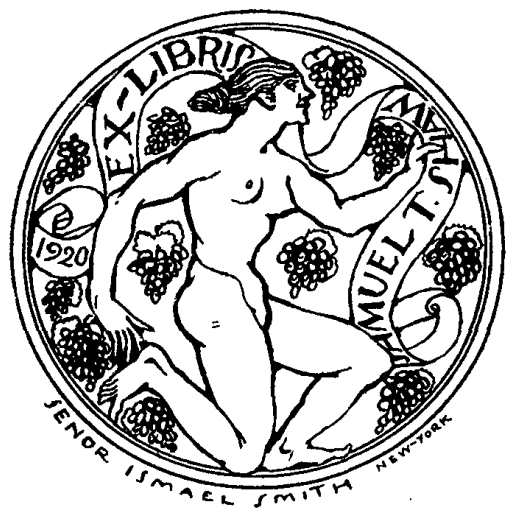

mayoría de esa población. ${ }^{3}$ En este sentido, el modus operandi de la diplomacia española en esta región se basó en la realización de gestiones casi siempre oficiosas que sólo en casos extremos adquirieron un carácter oficial, y en la congelación de los contenciosos bilaterales planteados con distintos países de la zona.

Paralelamente, la diplomacia espanola aprovechó el temor de la mayoría de los estados de la cuenca del Caribe para incrementar la influencia estadunidense en la misma, así como la ventaja que le proporcionaba su labor en la resolución de algunos de los conflictos territoriales que enfrentaban a distintos estados de la región. ${ }^{4}$ Sin

${ }^{3}$ Informe de la Sección de Política del Ministerio de Estado sobre la actitud de las repúblicas hispanoamericanas en la insurrección de Cuba, 1895-1896, [1896], AMAE, leg. H-2904.

${ }^{4}$ La mayor parte de los conflictos bilaterales estaban ocasionados por el endeudamiento de algunos de estos países con particulares españo- embargo, si bien la política española hacia el conjunto de la cuenca del Caribe giró en torno a los factores antes mencionados, dicha política debió adaptarse, en cada caso, a las particulares circunstancias que condicionaban la relación de España con cada uno de los estados de la región.

\section{LA POLITICA ESPAÑOLA HACIA HAITI Y LA REPÚBLICA DOMINICANA}

Desde el primer momento, España obtuvo el apoyo de las autoridades de las distintas colonias europeas existentes en las Antillas. Ello circunscribió la actividad de la diplomacia española en esta área a la República Dominicana y Haití.

El caso de la República Dominicana se planteaba a priori como el más problemático. La cercanía de este país con las costas de Cuba y Puerto Rico y la existencia en el mismo de un gran número de exiliados procedentes de las islas favorecieron que este estado adquiriera un interés primordial para la diplomacia española que se incre. mentó como consecuencia de las ne. gociaciones dominicano-cstadunidenses en torno a la bahía de Samaná, así como la ambigüedad inicial de las autoridades dominicanas hacia el proceso revolucionario que se desarrollaba en Cuba. ${ }^{5}$

les, o en las reclamaciones presentadas por inmigrantes españoles a causa de la frecuente inestabilidad política atravesada por gran parte de la región. Informe de la Sección de Política del Ministerio de Estado, 28 de nov. de 1895 , AMAE, leg. H-2896.

'Sobre dichas negociaciones véase Jiménes, Sociologia, 1974, vol. I, pp. 404-413. 
El régimen dominicano respaldaba oficialmente los esfuerzos de España por mantener su soberanía en Cuba. En este sentido, en abril de 1895, el gobierno presidido por Ulises Hereaux prohibía toda reunión "que tuviera por objeto tratar de Cuba o ser contraria a España". ${ }^{6}$ Un mes más tarde, el ministro dominicano en Madrid, José Ladislao Escoriaza, trasmitía al ministro de Estado, Carlos O'Donnell, duque de Tetuán, las garantías de su gobierno que impedían la organización de cualquier acción contra Cuba en su territorio.?

Sin embargo, ello no impidió que durante el primer semestre de 1895 la República Dominicana se convirtiera en una importante base de operaciones de los independentistas cubanos. En este marco, las autoridades locales toleraron la salida de expediciones hacia Cuba desde Barahona y San Pedro de Macorís, la creación de numerosas sociedades de solidaridad con Cuba y la multiplicación de los ataques a España por parte de la prensa dominicana. Esta situación no pasó inadvertida a las autoridades coloniales de Cuba y Puerto Rico, que comunicaron a Madrid la impunidad con que los independentistas cubanos parecían actuar en la República Dominicana. ${ }^{8}$

El riesgo que suponía prolongar esta situación condujo al gobierno español a destituir al cónsul en Santo

\footnotetext{
'Manuel José Quintana, cónsul general en Santo Domingo, a Tetuán, 24 de abr. de 1895 , AMAE, leg. H-2897. ibid.

${ }^{7}$ Escoriaza a Tetuán, 17 de mayo de 1895 ,

${ }^{8}$ A. Daban, gobernador de Puerto Rico, a Tetuán, 16 de mayo de 1895, ibid.
}

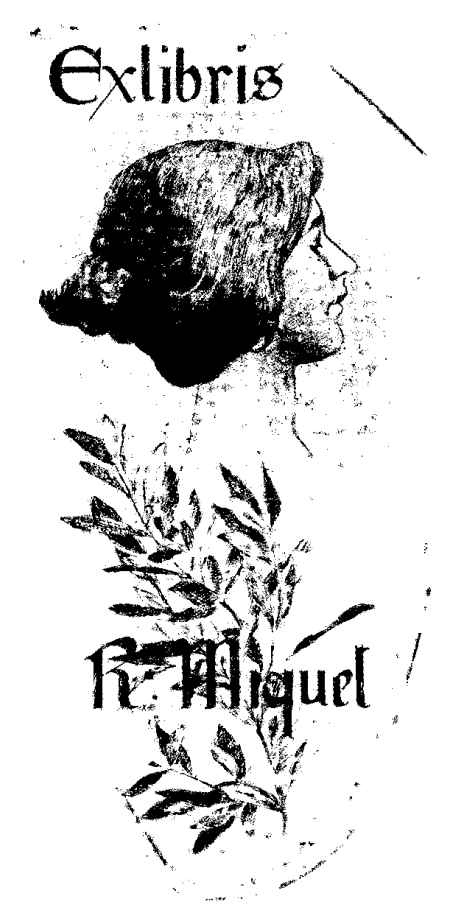

Domingo y a encargar al nuevo cónsul general, Francisco Lozano, una investigación sobre la actitud del gobierno dominicano hacia la cuestión cubana. Los resultados de dicha investigación señalaron que el gobierno dominicano había permitido la salida de dos expediciones hacia Cuba, había tolerado la aparición de diversos clubes cubanos en su territorio y mostraba gran tolerancia hacia los ataques de la prensa a España, pese a la prohibición de una circular expedida por el propio gobier- 
no en agosto de ese mismo año. Todo ello llevaba a Lozano a concluir que "el gobierno actual no ha dado pruebas de su supuesta adhesión a España"?

En este contexto, la diplomacia española debió adoptar una nueva estrategia hacia la República Dominicana, combinando medidas de presión con otras tendientes a reforzar los vínculos con el régimen dominicano. Con este objetivo, Lozano expuso al presidente dominicano el malestar de Madrid ante la pasividad mostrada por su gobierno y exigió la aplicación inmediata de un conjunto de medidas que, entre otras cosas, contemplaban la autorización a un barco de guerra español para ejercer "la vigilancia e inspección" de cualquier nave que se encontrara en aguas territoriales dominicanas y el compromiso de hacer observar la circular sobre publicaciones, de agosto de $1895 .{ }^{10}$

La posición del gobierno español se veía reforzada por el temor que tenía Hereaux de que las autoridades españolas comenzaran a apoyar las actividades de la oposición dominicana en el exilio. En este sentido, el establecimiento en Puerto Rico desde 1893 de un gran número de refugiados políticos dominicanos procedentes de Haití, tras el acuerdo de Manzanillo, proporcionaba a la diplomacia española un importante instrumento de presión sobre el dictador dominicano. ${ }^{11}$

${ }^{9}$ Lozano a Tetuán, 18 de sep. de 1895 , ibid.

${ }^{10}$ Lozano a Tetuán, 15 de sep. de 1895 , ibid.

¿El acuerdo de Manzanillo ponía fin a la utilización del territorio haitiano por la oposición dominicana en el exilio. Sobre las consecuencias de este acuerdo véase Jiménes, Socio-
La nueva política española comenzó a producir resultados a partir de octubre de 1895. En este marco, tras la llegada a las costas dominicanas del crucero español Marqués de Molins, el gobierno dominicano ordenó a los gobernadores de Montecristi, Puerto Plata, Samaná y San Pedro de Macorís cooperar con el comandante de dicho crucero en la represión del tráfico de armas hacia Cuba. ${ }^{12}$ Pocos días después, el vicepresidente dominicano, Wenceslao Figuereo, quien, según manifestaba el cónsul, "no perdonaba de poco tiempo a esta parte, medio ni ocasión de manifestar sus simpatías a España", prohibía los actos convocados para celebrar el aniversario del grito de Yara ${ }^{13}$ La colaboración del régimen dominicano con España no dejó de incrementarse a lo largo de 1896, como se puso de relieve ante el fracaso de la expedición preparada por los hermanos Néstor y Ángel Prado en Puerto Plata, la frustración de los proyectos del puertorriqueño José Bernardiny para apoderarse del vapor español María Herrera y las medidas adoptadas para impedir que el secretario de Máximo Gómez, Cesáreo Salas, pudiera apoyar a la expedición de Enrique Collazo. ${ }^{14}$

logía, 1974, vol. 1, pp. 431-432. Sobre las actividades del exilio dominicano en Puerto Rico véase Daban a Buenaventura Abarzuza, ministro de Ultramar, 13 de sep. de 1894, Archivo Histórico Nacional (en adelante AHN), Ultramar, leg. 5146-1.

${ }^{12}$ Escoriaza a Tetuán, 7 de oct. de 1895, AMAE, leg. $\mathrm{H}-2897$.

${ }^{13}$ Lozano a Tetuán, 24 de oct. de 1895, ibid.

${ }^{14}$ Informe de la Sección de Política del Ministerio de Estado, 27 de mar. de 1896, AMAE, leg. H-2901. 
Paralelamente, la consolidación interna del régimen dominicano puso fin a una de las principales preocupaciones de la diplomacia española en relación con este país, como era "el peligro de una intervención o protectorado del gobierno de Washington en la República Dominicana con grave riesgo de la independencia e integridad de la haitiana". ${ }^{15}$ En este sentido, el acceso de Hereaux a créditos europeos, en gran parte negociados a través de casas de comercio españolas establecidas en Santo Domingo y Barahona, llevó al presidente dominicano a abandonar públicamente su antiguo proyecto de arrendar la bahía de Samaná a Estados Unidos. ${ }^{16}$

El creciente acercamiento hispanodominicano permitió a la diplomacia española conseguir que Hereaux resistiera las presiones de la Junta Revolucionaria de Nueva York para que este país reconociera la beligerancia de los independentistas cubanos. En este sentido, Lozano logró que el presidente dominicano obligara a los parlamentarios más cercanos al exilio cubano a renunciar a cualquier intento de debatir en el Congreso la cuestión de la beligerancia o cualquier otra que afectara a España. ${ }^{17}$ En la misma línea, en abril de 1896, Hereaux se dirigió personalmente al presidente Stephen Grover Cleveland para exhortarle a que no se dejase arrastrar por las cámaras a una intervención en Cuba. El

${ }^{15}$ Lozano a Segismundo Moret, ministro de Estado, 15 de mar. de 1895, AMAE, leg. H-2060. 418.

${ }^{16}$ Jiménes, Sociología, 1974, vol. 1, pp. 416

17 Lozano a Tetuán, 22 de abr. de 1896, AMAE, leg. H-2901. presidente dominicano propuso a Washington que el conflicto fuera someticlo al arbitraje de un tribunal internacional, integrado por tres potencias europeas escogidas por España y tres naciones americanas designadas por listados Unidos. ${ }^{18}$

El gobierno español, por su parte, estrechó aún más la cooperación militar y diplomática con el régimen dominicano. Con este objeto, Madrid envió a Hereaux los oficiales navales que precisaba la naciente marina de guerra dominicana. ${ }^{19}$ Poco después, el Ministerio de Estado prometió a Hereaux utilizar su influencia diplomática con motivo del arbitraje papal en torno a la frontera haitiano-dominicana. ${ }^{20}$

Pese a que la represión desencadenada por Valeriano Weyler en Cuba provocó el éxodo de miles de cubanos a la República Dominicana, la diplomacia española mantuvo la colaboración de las autoridades de este país que, en noviembre de 1896 , confiscaron un importante cargamento de armas destinado a Cuba. ${ }^{21}$ En este marco, el principal motivo de inquietud para el gobierno español estaba conformado por la posibilidad de que Hereaux acabara cediendo a la creciente presión de la opinión pública

${ }^{18}$ Welles, Viña, 1938, vol. I, pp. 484-486.

${ }^{19}$ La estabilización de la situación hacendística dominicana permitió a Hereaux poner en marcha un ambicioso programa naval, comprando dos vapores armados de 500 . toneladas y encargando a unos astilleros británicos la construcción de un crucero de 1000 toneladas. Lozano a Tetuán, 15 de mar. de 1896, AMAE, leg. H-2060.

${ }^{20}$ Lozano a Tetuán, 22 de abr. de 1896, AMAE, leg. $\mathrm{H}-2901$.

${ }^{21}$ Lozano a Tetuán, 20 de nov. de 1896, ibid. 
de su país a favor de los cubanos. Sin embargo, estos temores resultaron infundados. Por una parte, el carácter autoritario del régimen dominicano minimizaba la incidencia de la opinión pública sobre el proceso de conformación de la política exterior de este país, que gravitaba exclusivamente en torno a la supervivencia del régimen político, objetivo para el que resultaba conveniente continuar contando con la colaboración financiera, militar y diplomática de España. ${ }^{22}$ Por otra parte, Hereaux comenzó a experimentar una creciente desconfianza hacia las actividades del elevado número de exiliados cubanos establecidos en la República Dominicana. La participación de algunos de los principales opositores al régimen dominicano, como Agustín Morales y Pablo Villanueva, en el movimiento revolucionario cubano alimentaba esta inquietud. ${ }^{23}$

Todo ello permitió a la diplomacia española mantener la colaboración de las autoridades dominicanas en la cuestión cubana hasta el inicio de la guerra hispano-estadunidense. En este sentido, Lozano no solo consiguió que se reprimiera cualquier reunión pública a favor de Cuba, sino que obtuvo la destitución de altos funcionarios dominicanos, como el gobernador de Puerto Plata, por su cercanía al exilio cubano y la expulsión del país de numerosos refugiados de esta isla. ${ }^{24}$ Finalmente, la diplomacia española logró que el

${ }^{22}$ Latorre, Política, 1979, pp. 50-52.

${ }^{23}$ Lozano a Tetuán, 30 de sep. de 1897, AMAE, leg. H-2903.

${ }^{24}$ Lozano a Tetuán, 22 de ene. de 1897 y 23 de mar. de 1897, ibid. gobierno dominicano delegara en las autoridades consulares españolas su representación consular en las Bahamas, dada la proximidad de los anteriores cónsules de este país a los exiliados cubanos establecidos en estas islas. ${ }^{25}$

También resultó conflictiva la posición adoptada inicialmente por el gobierno haitiano hacia la cuestión cubana.

Tras el estallido de la nueva crisis colonial, el representante español, Pedro Ortiz, consiguió que el gobierno haitiano diera al español garantías de impedir cualquier actividad contraria a la seguridad de las colonias españolas en las Antillas. ${ }^{26}$ En este sentido, en marzo de 1895, las autoridades haitianas prohibieron la celebración de una manifestación a favor de la independencia de Cuba y se comprometieron a impedir el tránsito de José Martí por su territorio. ${ }^{27}$

Sin embargo, al igual que sucedió en el caso de la República Dominicana, la posición del gobierno haitiano estuvo teñida de ambigüedad. En este sentido, pese a sus promesas, las autoridades de Haití toleraron el tránsito por Cabo Haitiano de José Martí y Máximo Gómez en su viaje hacia Jamaica, y permitieron el desarrollo de una campaña de prensa hostil a España. Estos hechos, unidos a la celebración en numerosas localidades del país de

\footnotetext{
${ }^{25}$ Lozano a Tetuán, 6 de abr. de 1897, ibid. Sobre las razones de dicha delegación véase Escoriaza a Tetuán, 10 de mar. de 1897, AMAE, leg. $\mathrm{H}-2382$.

${ }^{26}$ Ortiz a Tetuán, 1 de abr. de 1895, AmaE, leg. H-2896.

${ }^{27}$ Ortiz a Moret, 8 de mar. de 1895, ibid.
} 
actos y suscripciones a favor de la independencia de las colonias españolas, pusieron en evidencia la tolerancia del gobierno de Haití hacia las actividades de los separatistas cubanos en su territorio. ${ }^{28}$

La actitud del gobierno de Puerto Príncipe respondía a la necesidad de mantener el complicado consenso alcanzado por los distintos sectores de la oligarquía haitiana tras la caída de François Legitime. De esta manera, la actitud del gobierno de Florvil Hyppolite hacia la cuestión cubana estaba mediatizada por la popularidad que la causa de Cuba despertó inicialmente entre la burguesía mulata, especialmente poderosa en la capital y en el sur del país, así como entre determinados sectores de la propia administración, que veían en la revolución cubana un medio para liberar a la población negra de las Antillas que aún se encontraba bajo la opresión europea. ${ }^{29}$

Esta situación condujo al representante español a modificar radicalmente su actitud. De esta forma, desde mayo de 1895, Ortiz solicitó repetidamente el envío de un barco de guerra a Puerto Príncipe, mientras presionaba infructuosamente a las autoridades haitianas para que destituyeran al gobernador de Cabo Haitiano y expulsaran a los principales activistas cubanos de su territorio. El desencanto del cón-

${ }^{28}$ Guerra, Historia, 1952, vol. VI, p. 277 . Ortiz a Tetuán, 18 de mayo de 1895 y 16 de jun. de 1895, AMAE, leg. H-2896.

${ }^{29} \mathrm{La}$ incidencia de los factores raciales, regionales e ideológicos en la dinámica política haitiana durante este periodo puede seguirse en Grafenstein, Haití, 1988, pp. 138-150. sul español lo llevó a aconsejar al gobierno español que adoptara una actitud amenazadora frente a este país:

A este gobierno, lo mismo que al de Santo Domingo no se le mancja ni se consigue nada de ellos sino por el terror y día llegará para mí no lcjano en que la nación española tenga que hacer a este gobierno por su política ambigua, una formal reclamación. ${ }^{30}$

No obstante, la necesidad de contar con la cooperación del gobierno haitiano condujo a la diplomacia española a mantener una actitud prudente. En este contexto, el Ministerio de Estado rechazó enviar un crucero a Puerto Príncipe y ordenó al cónsul adoptar una posición menos beligerante hacia las autoridades haitianas. ${ }^{31}$ En dicha decisión debieron pesar las medidas conciliadoras adoptadas por el gobierno de Hyppolite para poner fin al incremento de la tensión con España. En este sentido, en mayo de 1895 , el presidente haitiano había ordenado a su representante en Madrid que comunicara al gobierno español la adopción por las autoridades haitianas, de las disposiciones necesarias para impedir la salida de expediciones hacia Cuba ${ }^{32}$ Poco después, el propio presidente ordenaba cerrar el diario $I^{\prime} E c h o$ D'Haití, que se había caracterizado por sus ataques a España, y obligaba a $L a$

${ }^{30}$ Ortiz a Tetuán, 18 de mayo de 1895, AMAE, leg. $\mathrm{H}-2896$.

${ }^{31}$ Informe de la Sección de Política del Ministerio de Estado sobre Haití, 30 de jul. de 1895, ibid.

${ }^{32}$ Georges Gentil, ministro haitiano en Madrid, a Tetuán, 18 de mayo de 1895, ibid. 
Press a abandonar su campaña a favor de la independencia de Cuba. ${ }^{33}$

Ello permitió que, durante la segunda mitad de 1895, comenzara a remitir la tensión entre los dos países. La llegada de un nuevo cónsul general, Alfonso Martínez de Tudela, no implicó cambios de importancia en la estrategia de la diplomacia española hacia este país. En este sentido, Martínez se limitó a vigilar las actividades de los exiliados cubanos para impedir que se tradujeran en un respaldo efectivo a la revolución que se desarrollaba en Cuba. El gobierno haitiano, por su parte, impidió que los activistas cubanos residentes en sú territorio em. prendieran cualquier acción directa contra Cuba, si bien continuó mostrando cierta permisividad hacia las reuniones y suscripciones organizadas por éstos.

La muerte de Hyppolite mientras se dirigía a reprimir un levantamiento liberal en Jacmel, en marzo de $\mathbf{1 8 9 6 ,}$ inauguró un periodo de incertidum. bre. El temor a que se produjeran desórdenes condujo al gobierno español a enviar el crucero Isabel II a Puerto Príncipe. ${ }^{34}$ Sin embargo, la elección como presidente del ministro de la Guerra, general Tiresias Simón Sam, en abril de ese mismo año, puso fin al vacío de poder existente y abrió la puerta a una mayor colaboración entre ambos países.

Los antecedentes del nuevo presidente de Haití parecían favorecer las

\footnotetext{
${ }^{33}$ Ortiz a Tetuán, 22 de jul. de 1895 , ibid.

${ }^{34}$ Martínez a Tetuán, 27 de abr. de 1896 , AMAE, leg. H-2900.
}

pretensiones españolas de incrementar la cooperación bilateral en torno a la cuestión cubana. En este sentido, en 1885 el nuevo mandatario, que desempeñaba el cargo de gobernador de Cabo Haitiano, había expulsado a varios exiliados cubanos a los que había decomisado un cargamento holandés de armas y municiones. ${ }^{35}$ Ello despertó ciertas expectativas en Martínez, de manera que, tan pronto como el nuevo presidente tomó posesión de su cargo, envió a un emisario para sondearle respecto a la postura que adoptaría hacia la cuestión cubana. Los resultados de dicha gestión no pudieron ser más favorables para los objetivos de la diplomacia española. El nuevo presidente haitiano consideraba que el desplazamiento de la presencia española en las Antillas provocaría un incremento de la influencia estadunidense en el Caribe, situación que consideraba como un verdadero peligro para su propio país:

Haga usted saber al cónsul de España, y eso, directamente de mi parte sin ambages ni rodeos, que de mi opinión y sentimientos respecto a su amable país en general y a la cuestión de Cuba en particular, responden de una manera positiva mis actos pasados. En cuanto a la línea de conducta que en adelante haya de seguir como presidente de esta República señalada, está contenicla en las consideraciones que no pueden dejar de ofrecerse al juicio, si es recto, cle todo gobernante patriota, en estos países vecinos del absorbente coloso, cuya codicia, más o menos disimulada, ibid.

${ }^{35}$ Martínez a Tetuán, 27 de abr. de 1896 , 
pero siempre alerta, es una amenaza constante a la ajena independencia. ${ }^{36}$

El comandante del Isabel II y el cónsul visitaron pocos días después al nuevo presidente haitiano, quien les confirmó la disposición de su gabinete a incrementar la cooperación con España en torno a Cuba. En este sentido, Simón Sam manifestó al representante español su intención de poner fin a los ataques de la prensa hacia España, para lo cual había ordenado que, en adelante, los artículos referidos a este país pasaran por la censura previa del ministerio del Interior. ${ }^{37}$ Un mes más tarde, Martínez de Tudela informaba a Madrid que Simón Sam, no sólo se mostraba sumamente receptivo hacia las gestiones del cónsul, sino que, al término de una recepción en el palacio presidencial, el máximo mandatario haitiano había brindado públicamente "a la definitiva victoria de nuestro ejército en Cuba". 38

La actitud del gobierno repercutió sobre las actividades de la reducida colonia cubana en este país, que, con notables excepciones, estaba integrada por gentes de color con escasos recursos e influencia. Por otra parte, la causa cubana encontraba menor eco en Haití que en otros países de la cuenca del Caribe. El temor a que una generalización del conflicto provocara el cierre de los mercados europeos, en un

\footnotetext{
${ }^{36}$ Ibid.

${ }^{37}$ Informe de la sección de política del Ministerio de Estado sobre la actitud de las repúblicas americanas en la insurrección de Cuba, s.f. [1896], AMAB, leg. H-2904.

${ }^{38}$ Martínez a Tetuán, 29 de mayo de 1896 , AMAE, leg. H-2023.
}

momento en que se acentuaba el desplome de los precios del café en el mercado internacional, condujo a la oligarquía liberal haitiana a retirar su respaldo al movimiento independentista cubano, como puede deducirse del cambio de línea editorial del diario oficialista Le Petit Peuple. ${ }^{39}$

Desde este momento, la receptividad mostrada por el nuevo presidente haitiano hacia las reclamaciones españolas, derivada, en gran medida, del temor a un incremento de la influencia de Estados Unidos sobre la región, unida a la escasa importancia revestida por el exilio cubano en Haití, impidieron que en este país llegaran a organizarse nuevas actividades contra los intereses de España en las Antillas. La actitud amenazante de Alemania a raíz del incidente Lüders, en septiembre de 1897 , y la creciente intervención del gobierno estadunidense en los asuntos internos de Haití facilitaron el mantenimiento de la colaboración del gobierno haitiano con España hasta el estallido de la guerra hispanoestadunidense. ${ }^{40}$

\section{la Diplomacia española en México}

El inicio de la nueva crisis colonial situó a México en el centro de atención de la diplomacia española. La política

\footnotetext{
39 Martínez a Tetuán, 3 de sep. de 1896, AMAE, leg. H-2900.

${ }^{40}$ La crisis haitiana-alemana se produjo a raíz de las sanciones impuestas por las autoridades haitianas a un comerciante alemán que había obstaculizado la detención de unos perseguidos. Martínez a Tetuán, 31 de ago. de 1897, AMAE, leg. H-2023.
} 
española hacia este país durante el desarrollo de la crisis cubana tuvo tres vertientes. Por una parte, el gobierno español presionó a la administración mexicana para que impidiera la utilización de su territorio como base de operaciones de los independentistas cubanos. Por otra, Madrid encomendó al ministro español, José Brunetti, duque de Arcos, que promoviera la movilización de la influyente colonia española radicada en este país, en un intento de erigir a la misma como grupo de presión frente a las simpatías que la causa cubana despertaba entre la mayoría de la opinión pública mexicana. Finalmente, la diplomacia española trató de conseguir el apoyo de un sector de la opinión pública de este país mediante el desarrollo de una intensa campaña de prensa.

Respecto al primer punto, la diplomacia española adoptó una actitud sumamente prudente en las gestiones que realizó ante el gobierno mexicano en relación con la cuestión cubana. En este sentido, las instrucciones trasmitidas desde Madrid al duque de Arcos enfatizaban la necesidad de que éste circunscribiera su actividad a un plano oficioso y confidencial:

La acción diplomática debe ser muy escasa y no traspasar nunca el carácter confidencial y oficioso $[\ldots]$ sólo por excepción podrá dar carácter oficial a las observaciones que formule, si bien tanteará siempre la cuestión en el terreno oficioso antes de imponer reclamaciones oficiales y escritas. ${ }^{11}$

${ }^{41}$ Tetuán a Arcos, 7 de jul. de 1896, AMAB, leg. H-1657.
Esta estrategia se reveló eficaz, pues evitó conflictos bilaterales en un momento delicado y permitió al gobierno mexicano presentar como producto de su propia iniciativa todas aquellas resoluciones que favorecían a España en esta cuestión. De esta manera, la diplomacia española evitó que las decisiones del régimen porfirista relativas al conflicto cubano pudieran ser mediatizadas por la presión de los sectores más nacionalistas de la opinión pública mexicana. La legación española consiguió de este modo un amplio respaldo por parte del gobierno presidido por Díaz. En este sentido, las autoridades porfiristas no sólo rechazaron las presiones dirigidas al reconocimiento de la beligerancia de los revolucionarios cubanos, sino que facilitaron al ministro español la información proporcionada por agentes de policía infiltrados en los círculos cubanos en México, extremaron las medidas de control aduanero, ordenaron vigilar los embarques de armas, reprimieron manifestaciones favorables a la independencia de Cuba e, incluso, limitaron la libertad de acción de determinados medios de comunicación, cuando éstos traspasaron ciertos límites en sus ataques a España. En esta línea, el propio secretario de Relaciones Exteriores, Ignacio Mariscal, expresó al gobierno español "su seguridad y fe absoluta en el triunfo de las armas españolas". ${ }^{2}$ La colaboración

\footnotetext{
${ }^{42}$ Arcos a Tetuán, 15 de nov. de 1895, AMAE, leg. H-1657. Sobre la diplomacia porfirista hacia Cuba véase Rippy, "Pan-Hispanic", 1922, pp. 389-414; Gilmore, "Mexico", 1963, pp, 510-525. Rojas, "Política", 1996, pp. 783-805; Muñoz,
} 
del gobierno de Porfirio Díaz en la cuestión cubana no dejó de ser reconocida repetidamente por el duque de Arcos en sus informes a Madrid:

Cada vez que he requerido de este gobierno su ayuda en materia de vigilancia, ha puesto a mi servicio los medios de que dispone. Claro es que no puede clar lo que no tiene $y$ por consiguiente la vigilancia ha sido muy imperfecta [...] Aún así se han dado por este gobierno repetidas órdenes a las autoridades locales, en especial a las de Aduanas, para que impidieran cualquier acto que fuera contrario a las leyes internacionales. ${ }^{43}$

La dipiomacia española tuvo un éxito similar en la movilización de la influyente colonia española establecida en México. ${ }^{44}$ En este sentido, las gestiones efectuadas por el duque de Arcos tuvieron como resultado la multiplicación de las juntas patrióticas españolas en la totalidad del territorio mexicano y la recaudación de cuantiosas sumas entre los españoles residentes en México para contribuir al esfuerzo bélico español en Cuba. El envío de cientos de mulas a esta isla y el ofrecimiento de un torpedero a la marina española constituyeron el resultado más llamativo de esta campaña. ${ }^{45} \mathbf{L a}$ exaltación nacionalista que se apoderó

"Caribe", 1997, pp. 96-111 y Morales, Espacios, 1998, pp. 74-104.

43 Arcos a Tetuán, 15 de nov. de 1895, AMAE, leg. H-1657.

${ }^{44}$ Sobre la colonia española en México durante este periodo véase Pérez, "Inmigración", 1981, pp. 128-135 y Lida, Inmigración, 1997, pP. 47-74.

4s Morales, Espacios, 1998, pp. 84-85. de la mayoría de los españoles residentes en este país llegó al extremo de proponer al gobierno español la realización de una contribución voluntaria entre todos los españoles radicados en América, destinada a la construcción de una escuadra de guerra. ${ }^{46}$

Por el contrario, la campaña de prensa auspiciada por la legación española no tuvo un impacto significativo sobre la opinión pública mexicana, que en su mayoría siguió simpatizando con las actividades de los independentistas cubanos. Antes bien, el grado de exaltación alcanzado por la prensa española en México, integrada fundamentalmente por $E l$ Correo Español y $E l$ Español, así como el de diversos periódicos mexicanos propiedad de españoles, como El Popular, El Tiempo, El Día y El Gil Blas, desencadenó un agrio debate con aquellos sectores de la prensa mexicana favorables a la independencia de Cuba. Este hecho inquietó al duque de Arcos, que acabó enfrentándose con los sectores más radicalizados de la colonia española para evitar que su actitud provocadora acabara originando un conflicto con las autoridades mexicanas. ${ }^{47}$

Pese al éxito alcanzado en conjunto por la estrategia que siguió la diplomacia española en México, la llegada al poder del gobierno liberal presidido por Práxedes Mateo Sagasta imprimió un giro radical a la política es-

\footnotetext{
46 Proyecto de la Junta Patriótica Española de México, 20 de ene. de 1896, AMAE, leg. H-2343.

${ }^{47}$ Informe anónimo sobre la actitud de la prensa española en México, s.f. [1897], Archivo General de la Administración, sección Asúntos Exteriores (en adelante AGA), leg. 211.
} 


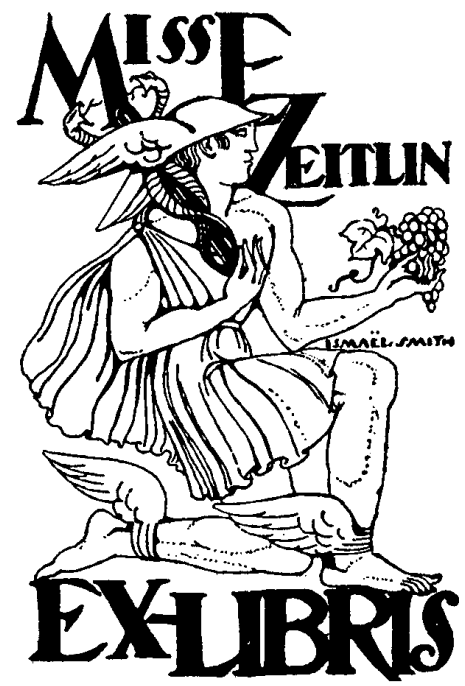

pañola hacia este país. El interés que ofrecía una hipotética alianza con México ante el inminente conflicto con Estados Unidos llevó al nuevo ministro de Estado, Pío Gullón, a sustituir al prudente duque de Arcos por el marqués de Bendaña. El nuevo representante español traía la misión de promover la creación de un sentimiento favorable a dicha alianza entre un sector de la clase política y de la opinión pública mexicanas. ${ }^{48}$ En la práctica, ello suponía un retorno a los planteamientos intervencionistas que habían condicionado la política española hacia México en décadas anteriores.

${ }^{48}$ Bendaña a Gullón, 12 de feb. de 1898, AGA, Asuntos Exteriores, leg. 235.
Sin embargo, el marqués de Bendaña no tuvo tiempo para desarrollar este proyecto. Pocos días después de su llegada, el estallido de la guerra hispanoestadunidense condujo al régimen de Díaz a adoptar una actitud de estricta neutralidad, dado que sus intereses, si bien eran contrarios a la extensión de la influencia estadunidense en las Antillas, excluían la posibilidad de un enfrentamiento directo con la vecina potencia. ${ }^{49}$ Ello llevó al Ministerio de Estado a encomendar al representante español que "tratara de producir complicaciones en la frontera, que pudieran dificultar la acción de Estados Unidos contra nosotros", recomendándole que obrase con reserva y utilizase para este propósito a los españoles residentes en México. ${ }^{50}$ No obstante, el marqués de Bendaña no se limitó a seguir las instrucciones recibidas de Madrid, sino que, con el respaldo del gobernador de Cuba que envió una comisión militar con este objeto, concibió un proyecto de gran envergadura:

Me dice el general Blanco que deja a lo que yo decida el que un cuerpo de españoles, unidos a fuerzas mexicanas de sus más intrépidos soldados, los $11 \mathrm{a}$ mados rurales, hicieran una sublevación en Texas, apoyando a los mexicanos que tan vejados se ven allí por sus conquistadores. ${ }^{51}$

49 Gilmore, "Mexico", 1963, pp. 512-513.

${ }^{30}$ Gullón a Bendaña, 18 de abr. de 1898 , AGA, Asuntos Exteriores, leg. 234.

${ }^{11}$ Bendaña a Martín Rosales, duque de Almodóvar y nuevo ministro de Estado, 2 de jun. de 1898, AGA, Asuntos Exteriores, leg. 235. Las actividades de las comisiones militares enviadas a México pueden seguirse en AGA, Asuntos Exteriores, leg. 237. 
El proyecto concebido por el representante español fue presentado para su estudio a la Dirección General de Política del Ministerio de Estado que consideró su ejecución problemática y sumamente peligrosa para las relaciones hispano-mexicanas. Ello llevó al gobierno español a desautorizar finalmente la realización de dicho proyecto. ${ }^{52}$ Pocos meses después, la pérdida de las colonias antillanas marcaría el final del interés geoestratégico que México había tenido para la diplomacia española.

\section{LA POLÍTICA EXTERIOR ESPAÑOLA HACIA CENTROAMÉRICA}

La nueva crisis colonial convirtió a esta región en otro de los polos de atención de la diplomacia española. La crisis cubana coincidió además con una de las fases más agudas del endémico conflicto fronterizo entre México y Guatemala. Ello condujo al represen: tante español en Centroamérica, Julio de Arellano, a ofrecer su mediación para la resolución del conflicto fronterizo. ${ }^{53}$ En contrapartida, la diplomacia española obtuvo del presidente guatemalteco, José María Reina Barrios, no sólo garantías de impedir en su territorio cualquier acto contrario a la soberanía española en las Antillas, sino el compromiso de que interpondría su in-

\footnotetext{
52 Gullón a Bendaña, 4 de mayo de 1898 , AGA, Asuntos Exteriores, leg. 235.

${ }^{53}$ La sede de la legación española en Centroanérica se encontraba en ciudad de Guatemala. Arellano a Moret, 12 de mar. de 1895, AMAE, leg. H-1608.
}

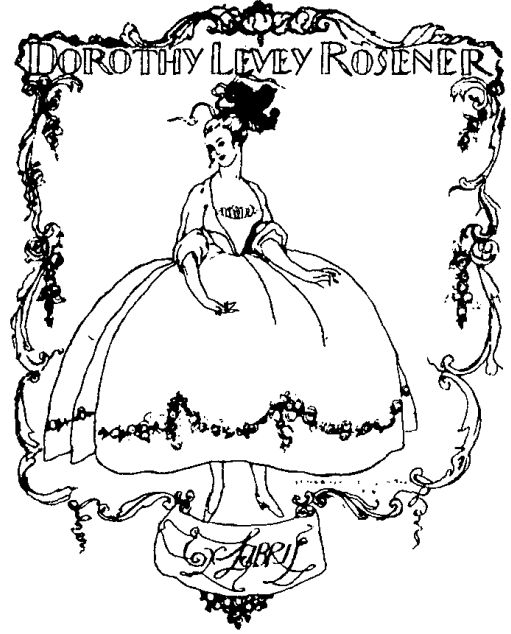

fluencia sobre las restantes repúblicas centroamericanas con este objeto. ${ }^{54}$

La diplomacia española también consiguió que los gobiernos de Nicaragua y Honduras mostraran desde el principio su disposición para impedir cualquier tipo de actividad dirigida contra las posesiones españolas en el Caribe. Este hecho era especialmente importante en el caso de Nicaragua, que había ocupado el año anterior el antiguo protectorado británico de Mosquitia, territorio que en el pasado había servido de refugio a los revolucionarios cubanos. ${ }^{55}$

\footnotetext{
${ }^{34}$ Arellano a Tetuán, 29 de mayo de 1895 , AMAE, leg. H-2895.

5s La anexión de la Mosquitia y el conflicto suscitado entre Nicaragua y la Gran Bretaña en 1894 puede seguirse en Karnes, "Nuevos", 1988, pp. 197-198. Sobre el compromiso adquirido con España por los gobiernos de Nicaragua $y$
} 
Sin embargo, durante los primeros meses de 1895, la diplomacia española recibió informaciones contradictorias en torno a la actitud del gobierno de Costa Rica hacia la cuestión cubana. El interés del gobierno español por evitar un deterioro de las relaciones con esta república, en un momento en que el movimiento revolucionario se extendía a la totalidad del este de Cuba, provocó la sustitución del cónsul español en San José. El nuevo agente consular, Luis Torres, recibió instrucciones de informar a Madrid sobre la verdadera posición del gobierno costarricense hacia la cuestión cubana y de poner fin al creciente deterioro de las relaciones bilaterales provocado por el enfrentamiento del anterior cónsul con las autoridades de este país. ${ }^{56} \mathrm{El}$ nuevo cónsul tomó posesión de su cargo en junio de 1895 y se apresuró a entrevistarse con el presidente de la república, Rafael Iglesias, quien reiteró su respaldo a España con motivo de la crisis de Cuba y aseguró que el gobierno de Costa Rica no estaba interesado en la independencia de Cuba:

[...] me ha referido que la política tradicional de Costa Rica consiste en el mantenimiento de la paz con España y con todas las demás potencias; que esta república no tiene interés alguno

Honduras véase Arellano a Tetuán, 29 de mayo de 1895, AMAE, leg. H-2895.

56 Tetuán a Torres, 21 de jun. de 1895, AMAE, leg. H-2897. Este deterioro se había producido a consecuencia de la salida de Antonio Maceo del país. Sobre las circunstancias que envolvieron a ta misma. Véase Guerra, Historia, 1952, vol. vI, pp. 266-271. en la independencia de Cuba y en que se constituya un nuevo estado en América; que no ha habido expediciones para aquella isla. ${ }^{57}$

Por otra parte, el contexto regional evolucionaba de forma cada vez más favorable a la diplomacia española. El 20 de junio de 1895, los presidentes de Nicaragua, Honduras y El Salvador firmaban el Tratado de Amapala. En virtud de dicho acuerdo estas tres repúblicas centroamericanas establecían las bases y plazos de una futura confederación: la República Mayor de Centroamérica. Ello polarizó a la región en dos bloques, pues Costa Rica y Guatemala se mostraron reticentes hacia dicho proyecto e iniciaron conversaciones bilaterales dirigidas al establecimiento de una alianza defensiva. ${ }^{58}$ En este contexto, ninguno de los dos bloques estaba interesado en provocar una crisis exterior con España que pudiera ser aprovechada por sus adversarios.

En este marco, en agosto de 1895 , se produjo el reemplazo de Arellano por Felipe García Ontiveros. El nuevo ministro español llegó a Guatemala a finales de septiembre de ese mismo año con la misión de mantener la colaboración de los gobiernos centroamericanos, establecida por su antecesor, e impedir que los exiliados cubanos de la región pudieran prestar un auxilio eficaz a la revolución cubana.

Con esta finalidad, García inició en diciembre de 1895 un periplo por los distintos estados de la región. 1il pri-

\footnotetext{
57 Torres a Arellano, 10 de jun. de 1895 , AMAE, leg. H-2895.

${ }^{58}$ Karnes, "Nuevos", 1988, pp. 197-199.
} 
mer destino del diplomático español fue Tegucigalpa, donde fue recibido el 23 de diciembre por el presidente, Policarpo Bonilla, quien en el curso de una larga entrevista reiteró su compromiso de impedir la salida de expediciones de hombres o armas hacia Cuba. ${ }^{59}$ La siguiente escala de este viaje fue Nicaragua. El 22 de enero de 1896 García llegaba a Corinto y era recibido por el vicepresidente y el ministro de Relaciones Exteriores que, con fuerte escolta militar, le acompañaron hasta Managua, donde lo recibió un día más tarde, el presidente Santos Zelaya. El país se encontraba al borde de una nueva guerra civil tras la escisión entre los liberales de León y Managua, pese a ello, el presidente nicaragüense prometió al representante español que su gobierno impediría por todos los medios a su alcance la salida de cualquier expedición hacia Cuba. ${ }^{60}$ García salió ese mismo día hacia San José de Costa Rica, a donde llegó el 31 de enero. La importancia del exilio cubano establecido en este país hacía del mismo un objetivo prioritario para la diplomacia española en la región. Ello condujo al ministro espanol a permanecer en Costa Rica durante varios meses.

Como vimos, la llegada del nuevo cónsul general a San José había frenado el creciente deterioro experimentado por las relaciones con este país. Siguiendo instrucciones de Madrid, el nuevo cónsul se había apresurado a adoptar una actitud conciliadora hacia

59 García a Tetuán, 25 de dic. de 1895, AMAE, leg. $\mathrm{H}-2900$.

${ }^{60}$ García a Tetuán, 12 de feb. de 1896 , ibid. el gobierno de Costa Rica, que, por su parte, había multiplicado los gestos de apoyo a España durante la crisis cubana. Sin embargo, Torres hubo de enfrentarse a los problemas provocados por la abierta simpatía de la opinión pública hacia la causa cubana. Este hecho fue organizado por los sectores más radicales de la oposición liberal, agrupados en torno al Partido Independiente Demócrata, dirigido por Félix Arcadio Montero. En este marco, entre septiembre y noviembre de 1895 , se produjo la aparición de clubes cubanos en la mayor parte de las ciuclades del país. Dichos centros fueron utilizados por la oposición liberal radical como plataforma para organizarse y preparar los trabajos preliminares para las próximas elecciones presidenciales. ${ }^{61}$

Paradójicamente, esta situación favoreció la posición española, pues llevó al gobierno costarricense a incrementar la vigilancia sobre el exilio cubano. En este marco, las autoridades comenzaron a aplicar con rigor la prohibición de recaudar fondos destinados a la insurrección cubana, prohibiendo una velada proyectada en Heredia con ese objeto. ${ }^{62}$ Paralelamente, el gobierno costarricense decidió dificultar las actividades de la oposición, imponiendo severas restricciones al funcionamiento de las sociedades de solidaridad con Cuba. En este sentido, en noviembre de 1895, el ministro de Gobernación, Juan J. Ulloa, reguló las actividades de dichas sociedades, que quedaron limitadas a

\footnotetext{
61 Torres a Tetuán, 9 de nov. de 1895, AMAE, leg. H-2897.

${ }^{62}$ Ibid.
} 
discutir teóricamente, desde el punto de vista de los principios, los asuntos relacionados con la independencia de Cuba, o recibir y comunicar noticias referentes a la revolución que allí tiene lugar. ${ }^{63}$

En esta misma línea, Torres consiguió que Iglesias ordenara a las autoridades locales:

que hagan vigilar las sesiones públicas de los clubes cubanos de su jurisdicción y les prohiban hacer colecta de fondos para la revolución, sea cual fuere la forma que con semejante fin adoptaren; que impidan por la fuerza toda recaudación de auxilios y que disuelvan cualquier reunión pública de dichos clubes en que se pronuncien discursos agresivos contra España y su gobierno. ${ }^{64}$

Por su parte, la diplomacia española comenzó una ofensiva periodística dirigida a la opinión pública de este país, mediante la publicación de $E l$ Pabellón Español, periódico subvencionado por la legación española en Centroamérica, y el apoyo de algunos medios cercanos al gobierno, como La Correspondencia. ${ }^{65}$ Todo ello supuso que la situación en Costa Rica a 1895.

${ }^{63}$ La Gaceta. Diario Oficial, 28 de dic. de

${ }^{6}$ Circular del Gobierno de Costa Rica de 28 de diciembre de 1895, en Torres a Tetuán, 29 de nov. de 1895, AMAE, leg. H-2897.

${ }^{65}$ El Pabellón Español trataba de seguir el ejemplo de la prensa española en México, convirtiéndose en el único periódico español en Centroamérica. Este periódico comenzó a publicarse en septiembre de 1895 por iniciativa del cónsul en San José. Torres a Tetuán, 19 de sep. de 1895, AMAE, leg. H-2897. la llegada del ministro español a San José, en enero de 1896, fuera, por tanto, sumamente favorable a los objetivos de la diplomacia española.

Los resultados de su viaje por los distintos estados centroamericanos permitieron a García transmitir al gobierno español una valoración positiva de la actitud de los gobiernos de esta región. En este sentido, el representante español en Centroamérica no dejaba de reconocer en sus informes a Madrid que la opinión pública de la totalidad de estos países era, de forma más o menos acentuada, favorable a la revolución cubana. Sin embargo, para el diplomático español este hecho resultaba irrelevante, dada la cooperación que los gobiernos centroamericanos prestaban a España en este asunto:

Puedo asegurar a V. E. que, si en todas ellas [en ref. a las repúblicas centroamericanas] más o menos acentuada, es propicia a los insurrectos la opinión pública, no es menos cierto que sus presidentes y sus respectivos gobiernos guardan una actitud correcta y amistosa para Espańa, y que puedo así mismo, consignar mi convencimiento de que las explotadas noticias referentes a envío, depósitos y ocultamiento de armas para Cuba en sus costas, son, en su casi totalidad, falsas y el resto en extremo exageradas. $^{66}$

Ello condujo a la diplomacia española a concentrar sus esfuerzos en mantener la colaboración de dichos gobiernos durante la fase final de la crisis cubana. Esta colaboración era especial-

${ }^{66}$ Garcia a Tetuán, 19 de feb. de 1896, AMAE, leg. H-2900. 
mente importante en el caso de Costa Rica, que recibió un número creciente de exiliados cubanos durante 1897.

En este contexto, las autoridades costarricenses no sólo incrementaron la vigilancia sobre los activistas cubanos establecidos en su territorio, sino que se apresuraron a reprimir cualquier actividad que rebasara el estrecho marco establecido por la circular de 28 de diciembre de 1895. Esta actitud respondía, en gran medida, al alineamiento del exilio cubano con el Partido Independiente Demócrata, que encabezaba la oposición a la reforma constitucional promovida por el gobierno para permitir la reelección de Iglesias en las elecciones presidenciales de 1898. En este sentido, la proximidad del exilio cubano al grupo "monterista" del Congreso, comprometido con el reconocimiento de la beligerancia de los revolucionarios antillanos, tuvo como contrapartida la hostilidad del ejecutivo. A ello se unió la inquietud de las autoridades de este país ante la llegada de numerosos refugiados cubanos, que huían de la represión desencadenada por Weyler en la colonia española. En este marco, el gobierno presidido por Iglesias impuso severas limitaciones a las actividades del exilio cubano en su territorio y reprimió cualquier manifestación pública a favor de la independencia de Cuba. ${ }^{67}$

La misma actitud mantuvieron el resto de las repúblicas centroamericanas que, a mediados de 1897, parecían entrar en una fase de distensión, tras la aceptación por los gobiernos de Guate-

${ }^{67}$ García a Tetuán, 18 de ene. de 1897, AMAk, leg. $\mathrm{H}-2903$. mala y Costa Rica, de un acuerdo para incorporarse a la proyectada República de Centroamérica. En este sentido, en junio de ese mismo año, el presidente guatemalteco volvió a reiterar su apoyo a España, manifestando públicamente que la crisis cubana era un problema interno de la antigua metrópoli y criticando la posición adoptada por el Congreso de Estados Unidos ante esta cuestión. ${ }^{68}$ Ese mismo mes, el gobierno de Honduras denegaba a un grupo de exiliados cubanos el permiso para fundar una colonia agrícola en este país, aduciendo las repercusiones que dicha autorización podría tener sobre las relaciones hispano-hondureñas. ${ }^{69}$

En este contexto, el proyecto de constitución de la República Centroamericana, firmado en Guatemala por los representantes de las cinco repúblicas en junio de 1897, encontró el apoyo de la diplomacia española, que, pese a su escepticismo acerca de las posibilidades reales de que dicho proyecto llegara a consolidarse, veía en el mismo un medio para que los débiles estados centroamericanos llegaran a constituir un bloque regional, que pudiera hacer frente a la creciente presión de Estados Unidos en la zona. ${ }^{70}$

Sin embargo, Centroamérica entró en una fase de gran inestabilidad a principios de 1898. Por una parte, la oposición que el proyecto de Unión

${ }^{68}$ García a Tetuán, 4 de jun. de 1897, AMAE, leg. H-1608.

69 Tetuán a García, 8 de jun. de 1897, AMAE, leg. H-2903.

${ }^{70}$ El interés español por la constitución de un bloque regional que estableciera una barrera frente a Estados Unidos databa de la década de 1880. MacGregor, México, 1991, pp. 38-39. 
Centroamericana suscitó en Costa Rica y Guatemala condujo a los parlamentos de ambos países a rechazar el acuerdo ${ }^{71}$ Por otra parte, el asesinato del general Reina Barrios produjo un vacío de poder en Guatemala que puso en duda la continuidad del apoyo de Guatemala a España. Paralelamente, la creciente tensión entre Costa Rica y Nicaragua amenazó con provocar un conflicto generalizado en toda la región. ${ }^{72}$

El brusco cambio de la coyuntura política en Centroamérica no constituía el único motivo de inquietud para la diplomacia española. El traslado a San Salvador de la Dieta de la República Centroamericana, organismo de carácter simbólico y competencias escasamente definidas, integrado por representantes de Nicaragua, Honduras y El Salvador, facilitó las gestiones de los activistas cubanos para que este organismo se pronunciase a favor del reconocimiento de la beligerancia de Cuba. La pasividad mostrada por el gobierno salvadoreño obligó al representante español a trasladarse a San Salvador en febrero de 1898. De esta manera, García consiguió evitar que la agitación de la colonia española diese lugar a nuevos incidentes y obtuvo el apoyo del presidente salvadoreño para neutralizar la creciente influencia cubana sobre la fantasmal asamblea centroamericana. ${ }^{73}$

Ello permitió a la diplomacia espanola mantener la colaboración de las repúblicas centroamericanas hasta el

71 Karnes, "Nuevos", 1988, p. 200.

${ }^{72}$ García a Gullón, 3 de feb. de 1898, amar, leg. H-1608.

${ }^{73}$ García a Gullón, 31 de mar. de 1898, ibia. estallido de la guerra hispano-estadunidense. Este conflicto planteó un nuevo escenario que supeditaba la resolución de la cuestión cubana al previsible desarrollo del mismo.

\section{la diplomacia española en el Caribe SUDAMERICANO}

Venezuela planteaba la situación más conflictiva para la diplomacia española. Las relaciones hispano-venezolanas habían experimentado un considerable deterioro desde mediados de 1894 a consecuencia del laudo arbitral dictado por el gobierno español en el conflicto fronterizo entre Colombia y Venezuela. ${ }^{74}$

En este marco, el gobierno venezolano adoptó una actitud ambigua hacia la cuestión cubana, pues si bien oficialmente declaró observar el artículo 12 del tratado hispano-venezolano de 1845, que comprometía al gobierno de Caracas "a no consentir que desde su territorio se conspirara contra la seguridad de España y sus islas", permitió la formación de varios comités revolucionarios cubanos en su territorio y no puso obstáculos a la salida de un pequeño contingente expedicionario cubano-venezolano hacia Jamaica. ${ }^{75}$

Esta situación condujo a la diplomacia española a promover acciones

${ }^{74}$ Hernández, Historia, 1986, pp. 201-204

${ }^{75}$ Sobre el tratado de 1845 , vé:ase Germán de Ory, ministro español en Caracas, a Tetuán, 24 de oct. de 1895, AMAE, leg. H-1801. Sobre la creación de clubes cubanos en Venezuela y la salida de una expedición desde La Guaira, véase Carlos de España, encargado de negocios en Caracas, a Tetuán, 14 de abr. de 1895 y 5 de mayo de 1895, AMAE, leg. H-2894. 
que pusieran fin a la tensión existente entre ambos países. En este sentido, el gobierno español hizo retornar a su representante a Caracas, en un contexto de aislamiento internacional del régimen venezolano, y adoptó una actitud conciliadora hacia los conflictos bilaterales planteados por las actividades de los independentistas antillanos en la república sudamericana. De esta manera, el nuevo representante español, Antonio de Castro, evitó la presentación de protestas oficiales, recurriendo, en cambio, a la vía oficiosa y confidencial para la resolución de dichos problemas. ${ }^{76}$

Esta estrategia tuvo éxito y propició un acercamiento entre ambas partes durante los primeros meses de 1896. En este sentido, el gobierno venezolano en febrero de 1896, anunció la creación en Madrid de su tercera legación en Europa y el envío a la misma de una de las principales figuras políticas del país, el líder liberal Juan Pietri. Al mismo tiempo, el presidente venezolano, Joaquín Crespo, reiteró su disposición a impedir la organización de cualquier expedición hacia Cuba. ${ }^{77}$ En esta línea, el ejecutivo venezolano se opuso un mes más tarde a la propuesta presentada por un sector del Congreso para reconocer la beligerancia de los cubanos. Ello condicionó el sentido de la votación, pese a que la misma tuvo como trasfondo un clima favorable a la revolución cubana,

${ }^{76}$ Castro a Tetuán, 24 de feb. de 1896, AMAE, leg. $\mathrm{H}-1807$.

77 Pedro Ezequiel Rojas, ministro de Relaciones Exteriores, a Castro, 7 de feb. de 1896, AMAE, leg. H-1807. provocado por las discusiones que, poco antes, se habían desarrollado en las cámaras estadunidenses y ecuatorianas en torno a esta misma cuestión. ${ }^{78}$

La colaboración de las autoridades venezolanas fue acompañada de la organización por Castro de una extensa red de vigilancia en el litoral venezolano y en las colonias holandesas y británicas próximas al mismo. En este marco, el representante español acometió una importante reestructuración del servicio consular, reemplazando al cónsul en Curasao y estableciendo "centros de información confidencial en Curasao, Coro, Puerto Cabello, Maracaibo y La Guaira", así como en 'Trinidad. ${ }^{79}$

El cambio de actitud del gobierno venezolano y la actividad del nuevo representante español afectaron scveramente a las actividades de los exiliados cubanos y puertorriqueños en este país. Ello condujo a un sector del exilio antillano a buscar la ayuda de los revolucionarios de Colombia y Venezuela. Este hecho propició, a su vez, un estrechamiento de la colaboración en materia de seguridad entre el gobierno español y los de estos países, permitiendo que Madrid y Bogotá establecieran mecanismos conjuntos para la vigilancia de sus respectivos enemigos políticos en Venezuela. ${ }^{80}$

${ }^{78}$ Informe de la Sección de Política del Ministerio de Estado sobre la actitud de las repúblicas estadunidenses en la insurrección de Cuba, [1896], AMAE, leg. H-2904. Sobre dichas discusiones, véase Morales, Espacios, 1998, pp. 92-101.

${ }^{79}$ Castro a Tetuán, 14 de mar. de 1896, Amali, leg. H-2900.

${ }^{80}$ Castro a Tetuán, 8 de mayo de 1896 , ibid. 
Esta situación fue aprovechada por la diplomacia española, que desplegó una intensa actividad para mantener el respaldo de las autoridades venezolanas en la cuestión de Cuba. Por una parte, el ministro español trató de contrarrestar las simpatías de la opinión pública venezolana hacia la causa cubana mediante una campaña de prensa de carácter hispanoamericanista. Esta campaña, sostenida por $L a$ Bandera Española y, desde principios de 1897 , por diversos medios venezolanos, como The Venezuelan Herald, no tuvo éxito a la hora de crear un estado de opinión favorable a España entre un sector de la opinión pública venezolana. ${ }^{81}$ Por otra parte, Castro desarrolló una diplomacia de carácter personalista, centrada en el establecimiento de relaciones personales de carácter amistoso con los miembros más prominentes del equipo gobernante. Con este fin, el ministro espanol logró convertirse en uno de los principales referentes de la vida social de Caracas. Lo que, sin duda, se vio facilitado por el hecho de que Castro revistiera, durante la mayor parte de 1897, el carácter de decano del cuerpo diplomático acreditado en Venezuela $^{82}$ Finalmente, el representante español adoptó una actitud sumamente flexible en sus relaciones oficiales con el gobierno de Caracas. De esta manera, Castro continuó congelando el planteamiento de los conflic-

${ }^{{ }^{1} 1}$ Castro a Tetuán, 26 de ene. de 1897, ibid. Sobre la actitud de la prensa venezolana hacia la cuestión cubana, véase Sánchez, Imagen, 1994, pp. 252-255.

${ }^{A 2}$ Castro a Gullón, 22 de mar. de 1898, AMAE, leg. $\mathrm{H}-1807$. tos bilaterales pendientes. Esta actitud se extendió a las nuevas reclamaciones provocadas por los movimientos revolucionarios que se desarrollaron en Venezuela en $1897^{83}$

Esta triple estrategia permitió al representante de España obtener la adhesión del nuevo gobierno venezolano, cuyo ministro de Relaciones Exteriores, Juan Calcaño, garantizó a Madrid la continuidad de la política seguida hacia Cuba por la administración anterior ${ }^{84}$ En este contexto, la nueva administración bloqueó en la Comisión de Relaciones Exteriores del Senado una propuesta presentada por el legislativo del estado de Los Andes, en la que se excitaba al congreso federal a reconocer la beligerancia de los cubanos. ${ }^{85}$ Esta colaboración se mantendría hasta el inicio de la guerra hispano-estadunidense durante la cual las autoridades venezolanas, como el resto de los estados de la región, adoptarían una actitud neutral.

En el caso de Colombia, el inicio de la crisis cubana coincidió con una etapa de las relaciones bilaterales caracterizada por la intensa cooperación prestada por la diplomacia española al gobierno de Bogotá, tanto en un plano interno, a raíz de la mediación española durante la revolución de 1895, como en el ámbito internacional, donde el gobierno español resolvió de forma favorable a los intereses

${ }^{83}$ Informe de la Sección de Política del Ministerio de Estado, 23 de oct. de 1897, ibid. Carrera, Formulación, 1988, p. 105.

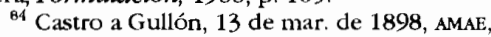
leg. $\mathrm{H}-1807$.

${ }^{B 5}$ Castro a Gullón, 30 de mar. de 1898, AMAE, leg. H-2904. 
colombianos los conflictos de este país con Venezuela e Italia. ${ }^{86}$

En este contexto, el respaldo del gobierno de este país a España durante la crisis cubana no ofreció dudas. Máxime, cuando las mayores simpatías hacia la causa cubana se encontraban entre los sectores liberales derrotados en la reciente revolución. Ello permitió al nuevo representante español, Agustín de la Barre, conseguir del gobierno colombiano el compromiso formal de perseguir cualquier actividad contraria a la seguridad de las Antillas españolas. ${ }^{87}$

Las autoridades colombianas, interesadas en conservar el respaldo internacional que hasta ese momento les había prestado la diplomacia española, decidieron restringir considerablemente las actividades del exilio cubano en su territorio. La primera medida adoptada en este sentido fue la resolución del Poder Ejecutivo de 8 de noviembre de 1895, por la que el gobierno de este país prohibió "toda organización, reunión y suscripción de fondos que tuviera por objeto auxiliar a insurrecciones en el exterior". ${ }^{88}$ Poco después,

\footnotetext{
${ }^{86}$ Jacinto B. de Cólogan, ministro español en Bogotá, a Moret, 1 de mar. de 1895, AMAE, leg. $\mathrm{H}-1426$. En gran medida este acercamiento derivaba de la proximidad entre los regímenes políticos, representados en ambos países respectivamente por la restauración y la regeneración, cuya máxima expresión era la influencia de la Constitución española de 1876 sobre el texto colombiano de 1886. Palacios, Legitimidad, 1995, p. 47.

67 Barre a Tetuán, 6 de nov. de 1895, AMAE, leg. H-2894.

${ }^{B A}$ Diario Oficial de la República de Colombia, 9 de nov. de 1895, AGA, Asuntos Exteriores, leg. 228 .
}

el ejecutivo ordenó a las autoridades de los departamentos marítimos que colaboraran con los agentes consulares españoles y sometieran a una estrecha vigilancia las actividades de los separatistas cubanos en su territorio:

Resulta de todo punto necesario que haga observar a las autoridades de ese departamento la más escrupulosa vigilancia con el fin de hacer frustrar toda empresa que tienda a hacer llevar recursos para los revolucionarios cubanos o a favorecer expediciones de nuestro territorio que puedan comprometer la neutralidad que corresponde a Colombia observar en la actual contienda civil de Cuba. ${ }^{89}$

Ello provocó un creciente alineamiento de los independentistas antillanos con la oposición liberal, como pusieron de manifiesto los desórdenes que se produjeron en Panamá en noviembre de $1895 . .^{00}$ Las reticencias del gobierno colombiano hacia los exiliados antillanos establecidos en su territorio se incrementaron a raíz del descubrimiento en Estados Unidos de un cargamento de armas destinado a Colombia y de la implicación en los hechos de individuos vinculados al exilio cubano en Estados Unidos. ${ }^{91}$

Estos hechos condujeron al gobierno presidido por Miguel Antonio Caro a restringir aún más las actividades de los activistas cubanos en su territorio. De esta manera, las autoridades de Bo-

${ }^{89}$ Circular del ministerio de Relaciones Exteriores de Colombia, 10 de dic. de 1895, AMAE, leg. H-2899.

${ }_{90}^{0}$ Barre a Tetuán, 31 de ene. de 1896, ibid.

${ }^{91}$ Barre a Tetuán, 9 de ene. de 1896, AMAR, leg. H-2898. 
gotá decidieron poner fin a la campaña de prensa favorable a la causa cubana. En este sentido, el 20 de diciembre de 1895, el presidente colombiano enviaba a los gobernadores de los distintos departamentos una circular "sobre neutralidad y ciertas publicaciones", en la que prohibía la publicación de cualquier ataque a España y a su política en Cuba. ${ }^{2}$

La colaboración de las autoridades colombianas permitió a la legación española en Bogotá establecer una red de agentes en los puertos de Bolívar y Magdalena que impidiera el contrabando de armas hacia Cuba. ${ }^{93} \mathrm{El}$ barón de la Barre también logró organizar a la colonia española en este país. Ésta era poco numerosa y estaba integrada en su mayoría por inmigrantes canarios que, en general, poseían escasos recursos. Esta situación llevó al ministro a crear la Sociedad Española de Beneficencia en diciembre de $1895 .{ }^{94} \mathrm{El}$ nuevo organismo sirvió de elemento de cohesión a la colonia española en Colombia y facilitó, en abril de 1896, la constitución de la Junta Patriótica Española de Bogotá, seguida, pocos meses más tarde, por la creación de organismos similares en Panamá, Cartagena y Barranquilla. ${ }^{95}$

${ }^{92}$ Diario Oficial de la República de Colombia, 28 de dic. de 1895, AGA, Asuntos Exteriores, leg. 228.

${ }_{93}$ Barre a Tetuán, 24 de feb. de 1896, AMAE, log. H-2899.

${ }_{94}$ Caro fue nombrado "protector" de dicha sociedad. Barre a Tetuán, 27 de dic. de 1895, AMAE, leg. H-2894.

95 Barre a Ricardo Sainz, presidente de la Junta Patriótica Española de México, 6 de abr. de 1896, AMAE, leg. H-2343.
Por otra parte, la diplomacia española consiguió establecer la intensa influencia de la Iglesia colombiana sobre el gobierno de su país. In este sentido, el barón de la Barre obtuvo el apoyo de un sector del clero colombiano de origen español, considerado por el representante español como "casi la única y verdadera influencia que la Madre Patria conserva en Colombia". ${ }^{96}$ La diplomacia española siguió disponiendo asimismo de la influencia que le proporcionaba su labor como árbitro de los conflictos de límites entre Colombia y sus vecinos. En este sentido, en julio de 1896 , el gobierno colombiano propuso oficialmente al de Costa Rica la candidatura de España para delimitar la frontera entre ambos países. Paralelamente, Bogotá negociaba con los gobiernos de Lima y Quito un acuerdo para someter la resolución de sus conflictos de límites al arbitraje del gobierno español. ${ }^{97}$

Todo ello aseguró la continuidad del apoyo colombiano a España durante la fase final de la crisis cubana.

${ }^{96}$ Destacaron en este sentido los obispos de Panamá, Pasto y Pinara. Barre a Tetuán, 20 de alor. de 1896, AMAE, leg. H-1426. Solore la influencia de la Iglesia colombiana durante la Regeneración, véase Palacios, Legitimidad, 1995, p. 50 .

${ }^{97}$ Barre a Tetuán, 4 de ago. de 1896, AMAE, leg. H-1426. El desarrollo de la mediación espatnola entre Colombia y Costa Rica puede seguirse en AMAE, TR-470. Las negociaciones relativas a los límites entre Colombia, Perú y Ecuador pueden consultarse en AMAE, TR-472. Sobre la importancia del papel desempeñado por España en las negociaciones limítrofes de Colombia con sus vecinos, véase Freres, Colombia, 1990, pp. 10-11. 
De esta manera, en julio de 1896, Caro reafirmó en su mensaje al Congreso su "propósito inconmovible de no inmiscuirse en los asuntos privativos de otras naciones, respetando su independencia", ${ }^{88}$ Un mes más tarde, las cámaras rechazaban el reconocimiento de la beligerancia de los revolucionarios cubanos. ${ }^{99}$ La deferencia del gobierno colombiano hacia España llegaría hasta el extremo de publicar en el Diario Oficial las noticias proporcionadas por el representante español en torno a Cuba ${ }^{100}$ Esta discreta colaboración se extendió hasta el inicio de la guerra hispano-estadunidense y llevó a Caro a garantizar al gobierno español, en marzo de 1898, que Colombia no reconocería la beligerancia de los cubanos aunque llegase a estallar una guerra entre España y Estados Unidos. ${ }^{101}$

\section{CONCLUSIONES}

La diplomacia española dispuso distintas estrategias hacia la cuenca del Caribe durante el desarrollo de la última crisis colonial. En unos casos, el gobierno de Madrid utilizó la influencia que le proporcionaba su labor como mediador internacional en los conflictos diplomáticos que enfrentaban a los distintos estados de la región entre sí o con otras potencias. En

${ }^{98}$ Barre a Tetuán, 4 de ago. de 1896 , AMAE, leg. H-1426.

${ }^{99}$ Barre a Tetuán, 25 de ago. de 1896, AMAE, leg. H-2899.

${ }^{100}$ Barre a Tetuán, 17 de nov. de 1896, ibid.

${ }^{101}$ Barre a Gullón, 24 de mar. de 1898, AMAE, leg. H-2904. otros, la diplomacia española propició el establecimiento de mecanismos de cooperación militar o económica, más o menos intensos. Finalmente, los representantes españoles también consiguieron capitalizar en su propio beneficio la inquietud que despertaba en muchas administraciones de la región un incremento de la influencia estadunidense en la misma, así como su temor hacia los nexos establecidos por el movimiento revolucionario cubano con la oposición a algunos de los regímenes políticos de la región.

En alguna medida, casi todas estas estrategias estuvieron presentes en la política edificada por España hacia cada uno de los estados de la región. La diplomacia española combinó dichas estrategias con la adopción de una actitud sumamente prudente, sin renunciar por ello a una mayor presión diplomática en aquellos casos en que ésta se hizo necesaria, como sucedió con la República Dominicana.

Todo ello permitió al gobierno español contar con la cooperación de la totalidad de los estados de esta región durante el desarrollo de la última crisis cubana. De esta manera, ninguno de dichos estados llegó a reconocer la beligerancia de los separatistas cubanos, ni permitió que en su territorio se desarrollaran abiertamente actividades contrarias a la soberanía de España en Cuba y Puerto Rico. Esta actitud se prolongó hasta el inicio de la guerra hispano-estadunidense, en abril de 1898 , durante la cual la totalidad de los países de la cuenca del Caribe mantuvieron una actitud neutral que, en última instancia, favoreció los intereses españoles ya que difirió indefini- 
damente cualquier cambio de planteamiento en relación con la cuestión cubana.

\section{ARCHIVOS}

AHN Archivo Histórico Nacional, sección Ultramar, Madrid.

AGA Archivo General de la Administración, sección Asuntos Exteriores, Alcalá cle Henares.

AMAE Archivo del Ministerio de Asuntos Exteriores, Madrid.

\section{BIBLIOGRAFÍA}

-Carrera, Germán, Formulación definitiva del proyecto nacional, 1870-1900, Editorial Lagoven, Caracas, 1988.

-Freres, Clara L., Colombia y España. Una reseña de sus relaciones, Universidad de los Andes, Bogotá, 1990.

-Grafenstein, Johanna von, Haiti, Instituto Mora/Universidad de Guadalajara/ Alianza Editorial, México, 1988.

-Gilmore, N. Ray, "Mexico and the Spanish-American War", Hispanic American Historical Review, vol. XLIII, núm. 4, 1963, pp. 510-525.

-Guerra, Ramiro, Historia de la Nación Cubana, Editorial Historia de la Nación Cubana, La Habana, 1952.

-Hernández, D., Historia diplomática de Venezuela, Universidad Central, Caracas, 1986.

Jiménes, Juan Isidro, Sociología politica dominicana, 1844-1966, Editorial Taller, Santo Domingo, 1974.

-Karnes, Thomas, "Nuevos intentos unionistas" en Mónica Toussaint, Guatemala, Instituto Mora/Universidad de Guadalajara/Nueva Imagen, México, 1988, pp. 160-173.

-Latorre, Eduardo, Política dominica- na contemporánea, Instituto Tecnológico de Santo Domingo, Santo Domingo, 1979.

-Lida, Clara E., Tres aspectos de la presencia española en México durante el porfiriato, El Colegio de México, México, 1981.

Inmigración y exilio. Re. flexiones sobre el caso español, El Colegio de México, México, 1997.

-MacGregor, Josefina, México y España: del porfiriato a la revolución, Instituto Nacional de Estudios de la Revolución Mexicana, México, 1991.

-Morales, Salvador, Espacios en disputa. México y la independencia de Cuba, Secretaría de Relaciones Exteriores/Centro de Investigación Jorge L. Tamayo, México, 1998.

-Muñoz, Laura, "El Caribe y México a finales del siglo XIX, 1890-1898", Revista Mexicana del Caribe, núm. 3, 1997, pp. 74111.

-Palacios, Marco, Entre la legitimidady la violencia. Colombia 1875-1994, Norma, Bogotá, 1995.

-Pérez, Pedro, "La inmigración española a México" en Clara E. Lida, Tres aspectos de la presencia española en México durante el porfiriato, El Colegio de México, México, 1981.

-Rippy, J. Fred, "Pan-Hispanic Propaganda in Hispanic America", Political Science Quarterly, vol. XXXVI, 1922, pp. 389-414.

-Rojas, Rafael, "La política mexicana ante la guerra de Cuba (1895-1898)", Historia Mexicana, vol. XLv, núm. 4, 1996, pp. 783-805.

-Sánchez, Rafael et al., La imagen de España en América 1898-1931, Consejo Superior de Investigaciones Científicas, Madrid, 1994.

-Toussaint, Mónica, Guatemala, Instituto Mora/Universidad de Guadalajara/ Nueva Imagen, México, 1988.

-Welles, S., La viña de Nabotb: la República Dominicana, 1844-1924, Eclitorial El Diario, Santiago, 1938. 